\section{Cocoa-nut Pearls.}

REFERRING to the letter of Dr. Sydney J. Hickson, published in your paper of June 16 last (p. 157), I have the pleasure to communicate to you that I have a collection of fourteen cocoanut pearls (one of them I myself found in 1866 at Holontalo, North Celebes, in the endosperm of the seed of the cocoa-nut); two melati pearls (Jasminium sambac); one tjampaka pearl (Michelia longifolia), found in the flowers, according to the natives. One of the cocoa-nut pearls has a pear-shaped form, the length being $28 \mathrm{~mm}$. The common name amongst the natives for this kind of pearls is mustika.

Utrecht, September 6 .

\section{J. G. F. RIEDEL.}

\section{STARS WITH REMARKABLE SPECTRA.}

I.

No. 152 Schjellerup (D.M. $+46^{\circ}$ No. 1817).

Place $1887^{\circ}$, R.A. 12h. $39 \mathrm{~m}$. 47 s., Decl. $46^{\circ} 3^{\prime} \cdot 5 \mathrm{~N}$.

THIS star, No. 290 in Mr. Birmingham's Catalogue of Red Stars, may very fittingly be taken as a sample of the stars possessing spectra of the fourth type, to use Secchi's nomenclature, or of the second division of the third type, to follow Vogel's-spectra, that is, in which the prominent feature is a series of dark bands alternating with bright spaces, and in which the dark bands are, as a rule, sharp and dark on the less refrangible side, or that nearer the red, but which gradually fade away into nothingness on the more refrangible side, or that towards the violet. The present star, though not perhaps the one in which the series of bands is most completely developed, has yet a spectrum which is a very beautiful example of the type ; the bright interspaces, or zones as they are technically called, are vivid and striking, and the bands broad and dark, and it possesses the additional advantage that, though only of magnitude 5.5 , it is yet the brightest star of its class in the northern heavens.

The purpose of the accompanying diagram, in which the spectrum of 152 Schjellerup is seen side by side with that of Tebbutt's comet of I88I, and with a particular carbon spectrum, is to bring into prominence the meaning of the remarkable series of shaded bands which characterize it. In 1869 , Secchi had declared that these bands coincided as to position with the bands of the carbon spectrum; but, as Dr. Huggins shortly after stated that he had compared the spectrum of carbon with that of a

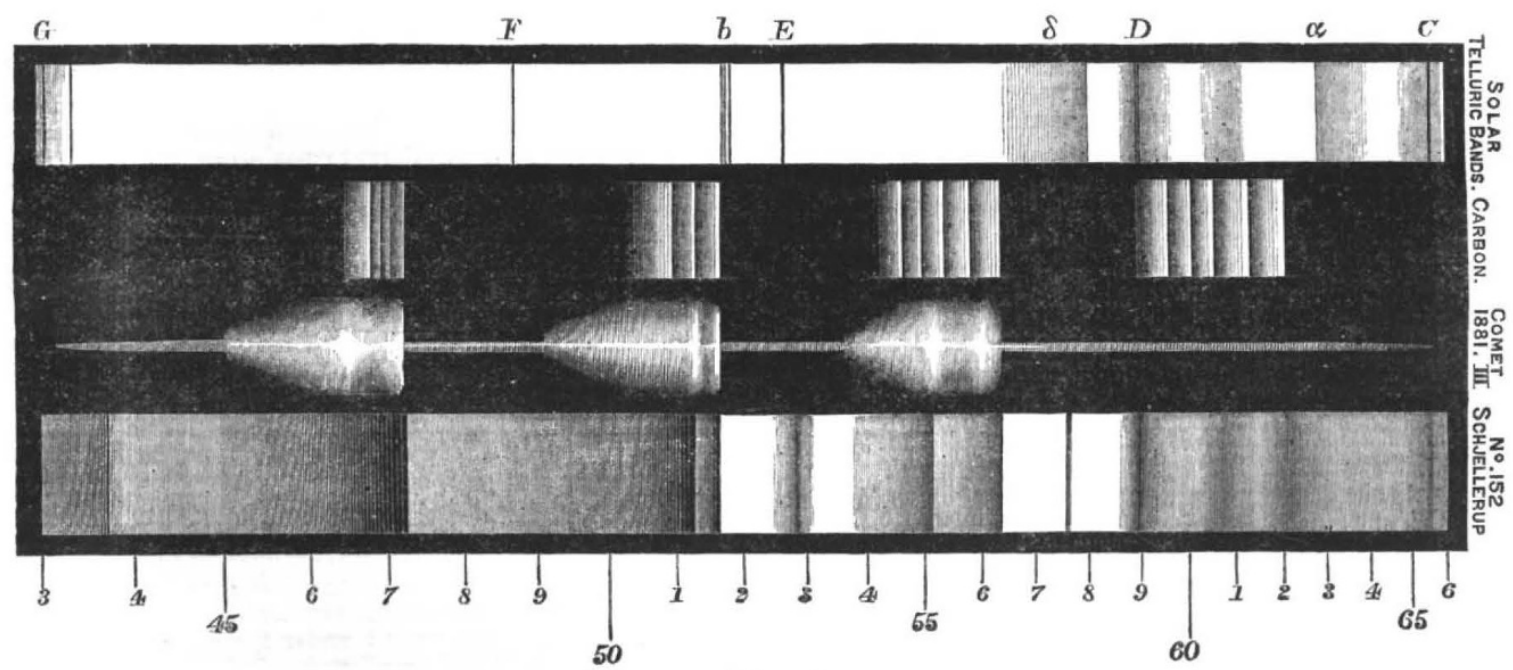

Scale of Wave-Lengths.

red star, and found that the two did not coincide, it was generally assumed that the Italian observer was mistaken, the well-known skill and accuracy of the great English spectroscopist rendering it very unlikely that his observation should be in error. As the event proved, both were right; it was only the natural inference that the two observations were contradictory that was at fault. Our knowledge of the beautiful and complicated spectra of carbon had not then attained its present precision, and it escaped remark that the spectrum with which Secchi had compared the red stars was not the same that Huggins had used for that purpose. Even now spectroscopists are not wholly unanimous as to whether we should reyard these two spectra as both belonging to elemental carbon at different temperatures, or as belonging to two different classes of carbon compoundsthose with oxygen and those with hydrogen. The spectrum which Secchi had used was that which, according to Thalén and others, characterizes the hydrocarbons ; whilst Huggins used that of the oxides.

The former spectrum is one which was already of high importance to the astronomer. Huggins had shown, in I868, by comparing Winnecke's comet with olefiant gas, that the three bright bands so typical of a comet coincided precisely with this form of the carbon spectrum; and now Dunér and Vogel have placed it beyond a doubt that in the spectrum of the red stars we see the same spectrum, only reversed-an absorption instead of an emission spectrum. The agreement as to the place of the sharp, well-marked, less refrangible edge of the three principal bands - the yellow, the green, and the blueis exact within the limit of errors of observation; the shading-off towards the violet is similar in character, and there are indications of the presence of some at least of the secondary flutings which in the carbon spectrum follow the great leaders of the bands in so charmingly rhythmical a manner. The orange band also, placed in a fainter part of the spectrum, and so more difficult to observe, is present, there can be little doubt, in the absorption spectrum of the red stars, though its bright analogue has seldom been satisfactorily traced in the spectrum of a comet; the violet band, on the other hand, appears to have been better seen in the comet than in the red star.

The following table will show the character of the correspondence of the principal bands of the three spectra- 
hydrocarbon, comet, and star. The wave-lengths are expressed in millionths of a millimetre :-

\begin{tabular}{|c|c|c|c|c|c|}
\hline $\begin{array}{l}\text { Colour } \\
\text { of }\end{array}$ & & $\begin{array}{c}\text { Comet } \\
\text { (Teb }\end{array}$ & & Typ & \\
\hline & & Copeland. $^{2}$ & Maund 2 . 3 & Dunér.4 & Vogel. 5 \\
\hline Orange & $\begin{array}{l}618 \cdot 7 \\
611.9\end{array}$ & & "A band & $621^{\circ} 0$ & $622^{\circ} 0$ \\
\hline & $605 \cdot 6$ & & half-way & $60+8$ & 606.5 \\
\hline & $600 \cdot I$ & & between & & \\
\hline & $595^{\circ} 4$ & & C and D." & & \\
\hline Yellow & $563 \cdot 3$ & $5^{6} 3 \cdot 2$ & $5^{5} 3^{\circ} \mathrm{O}$ & $5^{6} \cdot 3$ & $5^{6} 3^{\circ} \mathrm{I}$ \\
\hline & $\begin{array}{l}558 \% 3 \\
553.0\end{array}$ & $555^{\circ} 4$ & & & \\
\hline & $550 \%$ & & & $55^{\circ} \mathrm{O}$ & $55^{\circ} \circ$ \\
\hline & $546 \cdot 6$ & & & $545^{\circ} \mathrm{O}$ & $544^{\circ} \circ$ \\
\hline Green & $\begin{array}{l}5 \mathrm{I} 6 \cdot 4 \\
5 \mathrm{I} 2 \cdot 8 \\
509 \cdot 8\end{array}$ & $\begin{array}{l}516 \cdot 7 \\
513 \cdot 4\end{array}$ & $516 \cdot 3$ & $516 \cdot 3$ & $\begin{array}{l}515^{\circ} 9 \\
513^{\circ} 2\end{array}$ \\
\hline Blue & $\begin{array}{l}473 \cdot 6 \\
471^{\circ} \cdot 4 \\
469 \cdot 7 \\
468 \cdot 2\end{array}$ & $\begin{array}{l}473 \cdot 3 \\
467.5\end{array}$ & 4734 & $472 \%$ & $472 \cdot 9$ \\
\hline Violet & $43^{\prime} \cdot I$ & $430 \cdot 2$ & $\begin{array}{l}\text { "A band in } \\
\text { the violet } \\
\text { near G." }\end{array}$ & & $\begin{array}{l}\text { End of } \\
\text { spec- } \\
\text { trum. } \\
430^{\circ} 0\end{array}$ \\
\hline
\end{tabular}

Beside the above, there is in the spectrum of the star a faint band in the violet at $\lambda 437^{\circ} \circ$, which agrees according to Vogel, with a hydrocarbon band, not included in the above series.

The carbon bands thus account for the best-marked of the dark bands characteristic of the type, but there are three or four bands of a slightly different character which do not fall into the series. Thus, the green zone is interrupted by a narrow band at $\lambda 5^{2} 8^{\circ} \circ$, and the yellow zone by another at $\lambda 575 \% 7$ somewhat similar, both of which remain at present unexplained; and in the orange and red we find two bands in which the abrupt commencement on the red. ward side, and the gradual shading off towards the blue, is no longer apparent. The darkest part of the orange band is, indeed, near its centre, a dark line, coincident, there is scarcely any room to question, with the giant doublet of sodium, the great D lines of the solar spectrum. The red band, though without a nucleus which can be identified as a typical line of this or that element, gathers round the site of the red hydrogen line $\mathrm{C}$. The two bands therefore strongly recall, though the resemblance may perhaps be a misleading one, the great water-vapour groups around $C$ and $D$ in the absorption spectrum of our own atmosphere. The dry-air bands $a$ and $\delta-$ $A$ and $B$ being out of sight in the extreme red-do not appear to be represented. With a view to exhibit the relationship of these telluric bands to those in the less refrangible part of the spectrum of the typical red star, an outline of the solar spectrum has been added to the diagram, and the positions of the great Fraunhofer lines and of the principal bands due to the absorption of our own atmosphere have been indicated.

\section{THE BRITISH ASSOCIATION. SECTION D.}

\section{BIOLOGY.}

Opening Address by Alfred Newton, M.A., F.R.S., F.L.S., V.P.Z.S., \&C., Professor OF ZOOLOGY AND Comparative Anatomy in the Univeritty of CamBRIDGe, PResident of the Section.

In opening the business of this Section I cannot but call to mind the last occasion when the British Asiociation met in

I "Récherches sur les Spectres des Méta!loides."

${ }^{2}$ Copernicus, v 1 ii. p. 227 . 3 Obseriatory, y sl. iv. pp. $305,306$.

4 "Sur les Etoiles à Spsctres de la Tro.sième Classe," p. I22.

5 "Public. des Astroph. Obs. zi Pots lam," v 1 l. iv. p. ${ }_{3}$ r. the cify of Manchester, just six-and-twenty years ago ; and, while my memory brings back to me many pleasing recollections of that gathering, I cannot help dwelling upon the extravrdinary difference between the state of things that then existed and that which we have before us to-day. The moral of the contrast I shall not seek to enforce. Those, if any there still be, who despair of the future of our Association may reflect up on it at their leisure ; while those who believe, as I do, that our Association has no justifiable cause for thinking that its work is accomplished, that it had better settle its worldly affai 's, and compose its robes around it in a becoming fashion, before lying down to die, will at once appreciate the difference.

Yet there is one difference between our proceedings to-day and those of more than a quarter of a century since which I, personally, do not appreciate. In that remote and golden age it had not become obligatory on the President of this Section to prepare beforehand an address to be delivered to a critical, even though kindly, audience. A few words of friendly greeting to old faces, and a hearty welcome to those that were new, with a general statement of the objects of our conaing together, com prised all that was expected from the occupant of the chair. Such was my case when my predecessor, who was, I may observe, my excellent friend and colleague, Prof. Babington, opened the proceedings of this Section-then called the Section of Zoology and Botany-at Manchester in $186 \mathrm{I}$; and I am sure I have reason to envy his happy lot, for, on refreshing my memory by turning to the report of that meeting, I find that his introductory "remarks" occupy a space "of less than eight lines of print. In this respect, but in this only, I must confess myself luudator temporis acti, and it having now been for so many years the practice of your President to deliver an address on occasions like the present, I feel that I should be filling my po ition under false pretences did I not conform to established usage, though I am well aware that what I have to say will, for many reasons, hardly bear comparison with what has been said by many of my distinguished predecessors.

But to continue the contrast of what took place in this Section at our last meeting in Manchester with what may be expected to happen now, I would remark that the year I86I was one which, when the history of biology comes to be written, will be found to deserve particular recornition. This is not merely because of the all-important discovery of Arihaspteryx, for that had not been made known when the Association met, and did not affect our proceedings here. When we met, it was a time, so to speak, of "slack water"; but slack water is commonly the effect of two contrary streams, and perhaps I ought to state how this came about. All present should be aware that it was befo:e the Lin nean Society on July I, I 858 , that the stupendous announcement was made of a theory which for the first time brought to the notice of biolorists a reasonable explanation of the mode by which what had hitherto passed under the name of the transmutation of species could be effected. It is notorious that this announcement attracted but little attention at first, and, though it were easy to account for this fact, I see no need to occupy your time by so doing. I would, however, beg your attention to another fact which is by no means notori sus. So far as $I$ ain aware, the first zoologist publicly to accept and embrace the theory propounded on that memorable evening on behalf of $\mathrm{Mr}$. Darwin and $\mathrm{Mr}$. Wallace, was my old friend Canon Tristram, and moreover he did this ere little more than a twelvemonth hat expired (Ibis, October I859, pp. 429-433). To me it will always be a matter of rejoicing that the adoption of this theory was so early accepted, and additi nnal evidence in its favour adduced, by one who ha; devoted so much time and energy to the particular bran hh of zool igy which has long recommended itself to me; for thereby I hope that the study of ornithology may be said to have been lifted above its fellows. This, however, is a digression, for introlucing which I trust I may be pardoned. And now to return to my main business. Late in the autumn of 1859 , as you know, Mr. Darwin's essay on the "Origin of Species" appeared - a mere abstract, as it still remains, of an enormous mass of materials industriously accumulated by him through mony long years-a mass out of which, as he himself has modestly said, a competent man might have written "a sp'endid book"-but a mass with which he, chiefly through ill-health, had been unable to deal properly. Yet I am not sure that we have any reason to lament the result. The handy size of that celebrated little volume gave it a power of penetration and circulation that would not have been possessed by a work of greater bilk, while the studied absance of tech- 